\title{
Enhanced antitumor efficacy in colon cancer using EGF functionalized PLGA nanoparticles loaded with 5-Fluorouracil and perfluorocarbon
}

\author{
Pingping $\mathrm{Wu}^{\dagger}$, Qing Zhou ${ }^{\dagger}$, Huayun Zhu, Yan Zhuang and Jun Bao
}

\begin{abstract}
Background: Tumor recurrence and metastasis occur at a high rate in patients with colon cancer. Identification of effective strategies for the treatment of colon cancer is critical. Recently, poly (lactic-co-glycolic acid) (PLGA) has been shown to have potential as a broad therapeutic drug delivery system. We designed a dual-loaded nanoparticle drug delivery system to overcome the limitations of chemotherapeutic drugs used to treat colon cancer.

Methods: We developed epidermal growth factor (EGF) functionalized PLGA nanoparticles (NPS) co-loaded with 5fluorouracil (5Fu) and perfluorocarbon (PFC) (EGF-PLGA@5Fu/PFC) for targeted treatment of colon cancer. CCK-8 assay, Hoechst33342 staining and flow cytometry were performed to investigate the functions of EGF-PLGA@5Fu/ PFC NPs in SW620 cells. Beside, animal experiment, histological analysis and immunofluorescence staining were adopted to further confirm the role of EGF-PLGA@5Fu/PFC NPs in vivo.

Results: The findings showed that EGF-PLGA@5Fu /PFC NPs had an average size $200 \mathrm{~nm}$ and a 5Fu-loading efficiency of 7.29\%. Furthermore, in vitro release was pH-sensitive. Targeted EGF-PLGA@5Fu/PFC NPs exhibited higher cellular uptake than non-targeted NPs into colon cancer cells. In addition, EGF-PLGA@5Fu/PFC NPs suppressed cell viability and induced apoptosis in SW620 cells to a greater extent than non-targeted NPs. In tumor xenografted mice, EGF-PLGA@5Fu/PFC NPs suppressed tumor growth more effectively than 5Fu, PLGA@5Fu or PLGA@5Fu/PFC NPs. Histopathological analysis further demonstrated that EGF-targeted NPs inhibited tumor growth to a greater extent than non-targeted or non-NP treatments. The improved therapeutic outcomes observed in this study were due to relief of tumor hypoxia by transport of oxygen by PFC to the tumors.

Conclusion: We constructed a biocompatible nanodrug delivery system based on functionalized nanoparticles that provided a novel strategy for selective delivery of chemotherapy drugs to tumors.
\end{abstract}

Keywords: PLGA nanoparticles, 5-fluorouracil, Perfluorocarbon, EGF, Hypoxia, Colon cancer

\footnotetext{
* Correspondence: baojun@jszlyy.com.cn

'Pingping Wu and Qing Zhou contributed equally to this work.

Department of Medical Oncology, Jiangsu Cancer Hospital \& Jiangsu Institute of Cancer Research \& The Affiliated Cancer Hospital of Nanjing Medical University, Nanjing 210009, China
}

(c) The Author(s). 2020 Open Access This article is licensed under a Creative Commons Attribution 4.0 International License, which permits use, sharing, adaptation, distribution and reproduction in any medium or format, as long as you give appropriate credit to the original author(s) and the source, provide a link to the Creative Commons licence, and indicate if changes were made. The images or other third party material in this article are included in the article's Creative Commons licence, unless indicated otherwise in a credit line to the material. If material is not included in the article's Creative Commons licence and your intended use is not permitted by statutory regulation or exceeds the permitted use, you will need to obtain permission directly from the copyright holder. To view a copy of this licence, visit http://creativecommons.org/licenses/by/4.0/ The Creative Commons Public Domain Dedication waiver (http://creativecommons.org/publicdomain/zero/1.0/) applies to the data made available in this article, unless otherwise stated in a credit line to the data. 


\section{Background}

Colon cancer is one of the most common malignant cancers, and is associated with high morbidity and mortality worldwide [1]. Clinical therapeutic strategies for colon cancer include radiotherapy, chemotherapy and surgery. However, the efficacy of these therapeutic approaches is limited. Surgical intervention is associated with high rates of recurrence and metastasis [2]. Chemotherapeutic approaches often suffer from poor bioavailability, multidrug resistance and high system toxicity, which results in significant adverse effects and poor efficacy [3]. Therefore, development of effective strategies for the treatment of colon cancer is critical.

Nanoparticles have been shown to exhibit good biocompatibility and biodegradability, and significant progress has been made in the development of drug delivery systems in recent years [4]. Specific modification of the large surface area of nanoparticles could improve targeted delivery of chemotherapeutic drugs, and result in increased blood circulation time, which may improve outcomes [5]. Numerous nanoparticulate carriers, such as cyclodextrins, dendrimers and polymers have been developed for biomedical applications [6-8]. Poly (lacticco-glycolic acid) (PLGA), a polymer approved polymer by the Food and Drug Administration (FDA), has been extensively used as a drug carrier owing to its ability to encapsulate both hydrophobic and hydrophilic drugs [9]. As such, PLGA has shown potential as a drug delivery system for a wide range of therapeutic agents. A study used PLGA-based nanoparticles for delivery to the site of ischemia/reperfusion (I/R) injury, which led to anticoagulant and antioxidant effects for vascular therapy [10]. Furthermore, PLGA nanoparticles increased the accumulation of docetaxel at gastric tumor sites, which caused enhanced anticancer activity [11]. In addition, PLGA nanoparticles have been used for sustained and controlled drug delivery, improving bioavailability of hydrophobic compounds such as curcumin [12].

5 -fluorouracil $(5 \mathrm{Fu})$ is a widely used chemotherapeutic drug used to treat various cancers such as colon cancer and liver cancer $[13,14]$. As an antimetabolite analogue of pyrimidine, $5 \mathrm{Fu}$ has been reported to inhibit nucleoside metabolism and DNA synthesis, which results in cell apoptosis [15]. Moreover, 5Fu has been shown to modulate cell survival via the NF- $\mathrm{KB}$ pathway [16]. Nevertheless, clinical use of $5 \mathrm{Fu}$ is limited due to a short half-life, systemic adverse effects, the need for repeated doses to maintain therapeutic levels and non-selective delivery [17]. Hence, it is important to develop effective carriers to improve targeted delivery of $5 \mathrm{Fu}$, which may result in improved anti-cancer efficacy.

In the present study, we designed epidermal growth factor (EGF) modified PLGA nanoparticles containing $5 \mathrm{Fu}$ and oxygen-transport perfluorocarbon (PFC) to enhance therapeutic efficacy against colon cancer. These functionalized nanoparticles were constructed using a solvent evaporation technique and morphology, size distribution, in vitro stability and release profile were characterized. Cell uptake, cytotoxicity and apoptosis assays were used to evaluate the biological performance of nanoparticles. The distribution, growth suppression and histological changes induced by these nanoparticles were investigated in vivo using SW620 tumor-bearing mice. Finally, the potential mechanism by which these nanoparticles exerted enhanced antitumor effects was explored.

\section{Methods}

\section{Preparation of PLGA nanoparticles}

Solid-in-oil-in-water (s/o/w) dual emulsion solvent evaporation was used to prepare PLGA@5Fu/PFC NPs as previously described [18]. Briefly, $50 \mathrm{mg}$ of PLGA was dissolved in $2 \mathrm{~mL}$ of chloroform containing PFCs $(2 \mathrm{mg}$ ). Five $\mathrm{mg}$ of $5 \mathrm{Fu}$ was dissolved in $0.5 \mathrm{~mL}$ of aqueous solvent and the solution was mixed with PLGA solution to generate the s/o primary solution. The emulsion was dispersed in $10 \mathrm{~mL}$ of aqueous solvent containing $2 \% \mathrm{w} / \mathrm{v}$ PVA to generate the final s/o/w emulsion. Free PLGA/PVA polymers were separated by centrifugation at $3000 \mathrm{rpm}$ for $15 \mathrm{~min}$. The PLGA NPs were modified with EGF using $\mathrm{N}^{\prime}$-ethylcarbodiimide hydrochloride (EDC) [19].

\section{Characterization of nanoparticles}

The shapes of EGF-PLGA@5Fu/PFC NPs were examined using transmission electron microscopy (TEM) (Hitachi, Tokyo, Japan). A drop of NPs solution $(0.5 \mathrm{mg} /$ $\mathrm{mL}$ ) was mounted on a carbon-coated copper grid. The samples were observed at an acceleration voltage of 75 $\mathrm{kV}$. Size distribution and zeta potential were determined by dynamic light scattering (DLS, Zetasizer Nano ZS, Malvern Instruments Ltd., UK).

\section{Drug encapsulation and in vitro release}

The encapsulation efficiency of $5 \mathrm{Fu}$ in NPs was determined using a UV-Vis spectrophotometer (1800, Shimadzu, Kyoto, Japan). Briefly, $1 \mathrm{mg}$ of nanoparticles was dispersed in $1 \mathrm{~mL}$ of distilled water to extract $5 \mathrm{Fu}$. The solution was shaken gently for $12 \mathrm{~h}$ at $37^{\circ} \mathrm{C}$, the obtained filtrates were diluted (1:10) with methanol and the solution was analyzed at $\lambda \max =266 \mathrm{~nm}$. Encapsulation efficiency and loading efficiency were calculated using the following equations:

$$
\begin{aligned}
& \text { Encapsulation efficiency }(\%) \\
& =\frac{\text { Amount of } 5 \mathrm{Fu} \text { in nanoparticles }}{\text { Total } 5 \mathrm{Fu} \text { added }} \times 100
\end{aligned}
$$




$$
\text { Loading efficiency }(\%)=\frac{\text { Amount of } 5 \mathrm{Fu} \text { in nanoparticles }}{\text { Total nanoparticle weight }} \times 100
$$

The release profile of $5 \mathrm{Fu}$ from NPs was accessed at 2 $\mathrm{pH}$ values (5.0 or 7.4). Ten mg of NPs was dispersed in $10 \mathrm{~mL}$ of PBS, then transferred to a dialysis bag, which was placed in $50 \mathrm{~mL}$ of media and stirred at $37^{\circ} \mathrm{C}$. At predetermined time points, $2 \mathrm{~mL}$ of release medium was removed, with replacement. The amount of $5 \mathrm{Fu}$ released was determined using a UV-Vis spectrophotometer.

\section{Cell lines and culture}

The human colorectal cancer cell line SW620 was obtained from the Chinese Academy of Science (Shanghai, China). The SW620 cells were maintained in Dulbecco's Modified Eagle Medium (DMEM) supplemented with $10 \%$ fetal bovine serum (FBS). The cells were cultured in a humidified cell incubator in a $5 \% \mathrm{CO}_{2}$ atmosphere at $37^{\circ} \mathrm{C}$.

\section{In vitro cell uptake}

Human SW620 cells were cultured in 12-well plates at a density of $2 \times 10^{4}$ cells/well. After $24 \mathrm{~h}$, fresh DMEM with Cy5-labeled NPs (EGF-PLGA@5Fu/PFC and PLGA@5Fu/PFC) was added and the cells were cultured at $37^{\circ} \mathrm{C}$ for $2 \mathrm{~h}, 4 \mathrm{~h}$ or $6 \mathrm{~h}$. The cells were then washed with PBS, fixed using $4 \%$ paraformaldehyde and stained using DAPI. Finally, the cells were visualized using a confocal laser scanning microscope (CLSM).

\section{Cell cytotoxicity}

Human SW620 cells were cultured in 96-well plates at a density of $2 \times 10^{3}$ cells/well. After $24 \mathrm{~h}$, different formulations of NPs were added to the wells and the cells were cultured for $48 \mathrm{~h}$ at $37^{\circ} \mathrm{C}$. Then, $10 \mu \mathrm{L}$ of CCK- 8 was added to each well, and the cells were incubated for an additional $4 \mathrm{~h}$. Optical density was determined at 450 nm using a microplate reader (BioRad, Hercules, CA, USA).

\section{Hoechst 33342 staining}

Human SW620 cells $\left(1 \times 10^{4}\right.$ cells/well $)$ were seeded in 24-well plates, then treated with different formulations of NPs for $48 \mathrm{~h}$. Then, the cells were washed with PBS three times and stained with Hoechst $(2 \mu \mathrm{g} / \mathrm{mL})$ for 20 min at room temperature. Stained cells were visualized using a fluorescence microscope (Nikon TE2000; Nikon Corporation, Tokyo, Japan) (magnification, $\times 100$ ).

\section{Cell apoptosis}

Human SW620 cells $\left(1 \times 10^{5}\right.$ cells/well $)$ were cultured in 6-well plate with different formulations of NPs for $48 \mathrm{~h}$. Then, the cells were washed twice with PBS, and suspended in staining buffer containing propidium iodide
(PI) $(1 \mu \mathrm{g} / \mathrm{mL})$ and annexin V-FITC $(0.025 \mu \mathrm{g} / \mathrm{mL})$ for $15 \mathrm{~min}$ at room temperature. Apoptotic cells were evaluated using a FACScalibur flow cytometer (BD Bioscience, Franklin lakes, NJ).

\section{Animal model}

Female BALB/c mice (6-8 weeks, 20-22 g) were obtained from the Animal Laboratory of Nanjing University and were kept in standard conditions with humidity maintained at $50-60 \%$, temperature controlled at $25 \pm$ $2{ }^{\circ} \mathrm{C}$, a 12-h dark/light cycle and free access to water and food. All animal experiments were performed in accordance with the Guidelines for Care and Use of Laboratory Animals of the University of Science and Technology of China and approved by the Animal Ethics Committee of Nanjing Medical University.

Human SW620 cells $\left(3 \times 10^{6}\right)$ were resuspended in $100 \mu \mathrm{L}$ of PBS and injected into the right flanks of the mice. When the average tumor volume reached about $100 \mathrm{~mm}^{3}$, the mice were randomly assigned to 6 groups $(n=8)$ and administered with saline, blank NPs $(100 \mathrm{mg} / \mathrm{kg}), 5 \mathrm{Fu}(8$ mg/kg), PLGA@5Fu (8 mg/kg of 5Fu), PLGA@5Fu\&PFC $(8 \mathrm{mg} / \mathrm{kg}$ of $5 \mathrm{Fu})$ or EGF-PLGA@5FU\&PFC $(8 \mathrm{mg} / \mathrm{kg}$ of $5 \mathrm{Fu})$ once every 2 days. Tumor size was measured and tumor volume was calculated as follows: volume $\left(\mathrm{cm}^{3}\right)=$ Length $(\mathrm{L}) \times \mathrm{Width}^{2}\left(\mathrm{~W}^{2}\right) / 2$. At the end of the study, the mice were sacrificed by intraperitoneal injection of sodium pentobarbital $(100 \mathrm{mg} / \mathrm{kg})$, and the tumor and major organs were isolated for further analysis.

\section{In vivo fluorescence imaging}

At $24 \mathrm{~h}$ after injection, the mice were sacrificed and the biodistribution of the different formulations of drugs in the tumors and major organs was determined using a fluorescence imaging system.

\section{Histological analysis}

Mouse tissues from the mice were fixed in $10 \%$ formalin, embedded in paraffin and cut into $5-\mu \mathrm{m}$ sections. The sections were stained with hematoxylin and eosin (H\&E) to evaluate the histological changes in the tumors and major organs. For TUNEL assay, tumor tissues were stained using an in-situ apoptosis detection kit (Thermo Fisher Scientific) according to the manufacturer's instructions. For immunohistochemical staining (IHC), tumor tissues were incubated with the primary antibody against Ki-67 (ab15580, Abcam). Visualization of H\&E and IHC staining was performed using a light microscope, and for TdTmediated dUTP nick end labeling (TUNEL) was evaluated using a fluorescent microscope. 


\section{Immunofluorescence staining}

At the end of the study, the mice were intravenously injected with pimonidazole $(60 \mathrm{mg} / \mathrm{kg})$ for hypoxia staining. After $90 \mathrm{~min}$, tumors were collected, embedded in paraffin, and cut into $8-\mu \mathrm{m}$ sections. The tumor tissues were then incubated with the primary antibody against pimonidazole (1:200, Hypoxyprobe-1 Plus Kit, Hypoxyprobe, Burlington) at $4{ }^{\circ} \mathrm{C}$ overnight, then incubated with Alexa $\mathrm{Fluo}^{\circ} 488$ conjugated goat-anti-mouse antibody (1: 500 , ab150113, Abcam) for $1 \mathrm{~h}$ at $37^{\circ} \mathrm{C}$. Nuclei were counterstained with DAPI for $3 \mathrm{~min}$. Images were captured using a fluorescence microscope (magnification, $\times 200$ ).

\section{Statistical analysis}

All data were analyzed using GraphPad Prism 5.0 and presented as mean \pm standard deviation. One-way ANOVA analysis followed by Tukey's post hoc test was used to compare differences between among multiple groups. $P<0.05$ was considered statistically significant.

\section{Results}

\section{Characterization of nanoparticles}

To prepare EGF-PLGA@5Fu/PFC NPs, 5Fu was encapsulated in PLGA polymer using the double emulsification solvent evaporation method. The morphology of $5 \mathrm{Fu}$ loaded PLGA NPs was observed using TEM (Fig. 1a). The nanoparticles were monodisperse and spherical, with an average a size around $200 \mathrm{~nm}$. Dynamic light scatter analysis confirmed that the average diameter of EGF-PLGA@5Fu/PFC NPs was $200 \pm 10.84 \mathrm{~nm}$, with a narrow distribution (Fig. 1b). Zeta potential analysis showed that EGF-PLGA@5Fu/PFC NPs had a negative surface charge of $-23.7 \pm 1.4 \mathrm{mV}$. The encapsulation efficiency and drug loading efficiency were $81.6 \pm 5.7 \%$ and $7.29 \pm 0.14 \%$, respectively. The release profile of $5 \mathrm{Fu}-$ loaded PLGA NPs was determined at $2 \mathrm{pH}$ levels (5.0 or 7.4). The nanoparticles exhibited a biphasic drug release pattern with initial accelerated release followed by sustained release over 7 days. As shown in Fig. 1c, $45 \%$ of $5 \mathrm{Fu}$ was released from EGF-PLGA@5Fu/PFC NPs within 6h, and
$80 \%$ of $5 \mathrm{Fu}$ was released within 7 days at $\mathrm{pH}$ 5.0. In contrast, EGF-PLGA@5Fu/PFC NPs exhibited slow drug release at pH 7.4, which indicated that EGF-PLGA@5Fu/PFC NPs could rapidly release $5 \mathrm{Fu}$ in the acidic conditions common to cancer cells.

\section{In vitro cellular uptake}

The presence of surface EGF allows EGF-PLGA@5Fu/ PFC NPs to interact strongly with EGFR, which results in anchoring of these NPs to cancer cells that express high levels of EGFR. To determine check the targeting ability of EGF-PLGA@5Fu/PFC NPs, SW620 cells were incubated with Cy 5 labeled NPs for $2 \mathrm{~h}, 4 \mathrm{~h}$ or $6 \mathrm{~h}$ after pretreatment free EGF or with no pretreatment. The cellular uptake of EGF-PLGA@5Fu/PFC NPs was determined using CLSM. As shown in Fig. 2, the fluorescence intensity of the non-pretreated cells incubated with EGF-PLGA@5Fu/PFC NPs was stronger than that of non-targeted NPs (PLGA@5Fu/PFC), and uptake increased in a time-dependent manner, which suggested greater adsorption of EGF-PLGA@5Fu/PFC NPs to colon cancer cells. To further characterize the role of EGFR on cell surface in binding of EGF-PLGA@5Fu/ PFC NPs, competition with free EGF was evaluated by pretreating SW620 cells with a high concentration of EGF $(100 \mu \mathrm{g} / \mathrm{mL})$ for 1 day. The results showed that pretreatment with EGF significantly decreased uptake of EGF-PLGA@5Fu/PFC NPs into SW620 cells compared with that into non-pretreated cells as evidenced by the relatively weaker fluorescence intensity. This result confirmed that the binding efficiency of EGF-PLGA@5Fu/ PFC NPs to cancer cells was positively associated with EGFR expression level. These results showed that EGFPLGA@5Fu/PFC NPs effectively increased the cellular uptake via EGF receptor-mediated endocytosis.

\section{In vitro cell cytotoxicity and apoptosis}

To investigate the antitumor effects of 5Fu-loaded NPs in vitro, SW620 cells were cultured and incubated with
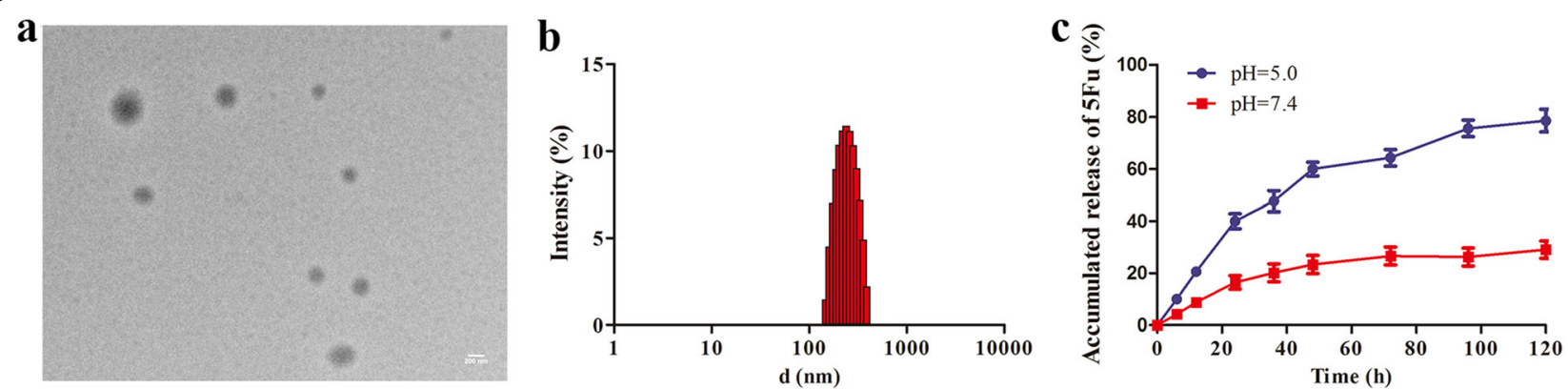

Fig. 1 Characterization of EGF-PLGA@5Fu/PFC NPs. a The morphology of EGF-PLGA@5Fu/PFC NPs was evaluated using TEM. b Size distribution of EGF-PLGA@5Fu/PFC NPs was determined by DLS. c In vitro release of 5FU from EGF-PLGA@5Fu/PFC NPs at different pH levels was monitored by a UV-Vis spectrophotometer 


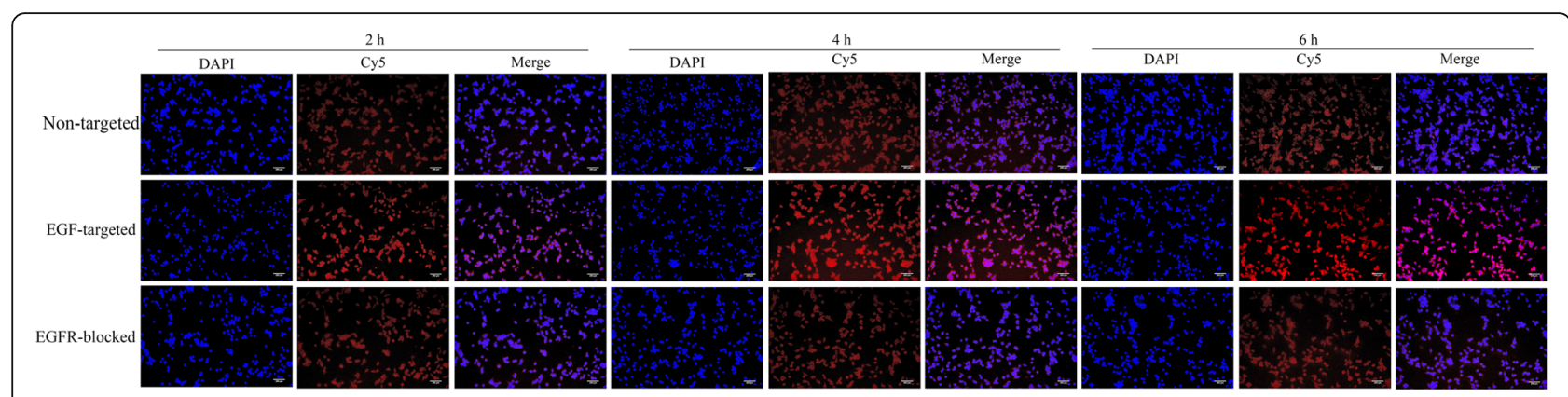

Fig. 2 In vitro cellular uptake of EGF-PLGA@5Fu/PFC NPs to SW620 cells was visualized using a confocal laser scanning microscope (magnification, $\times 200)$

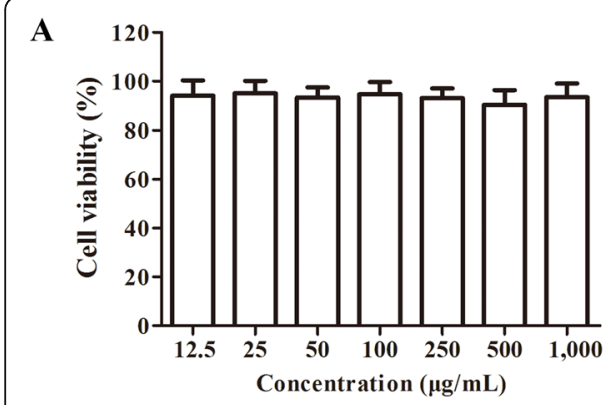

B

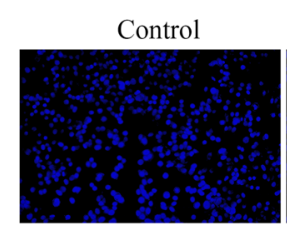

C

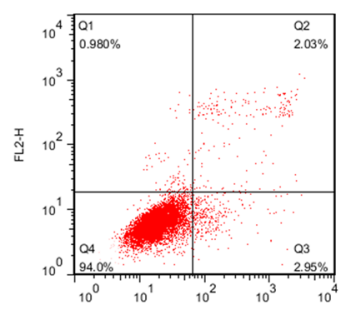

FI1-H" ANNFXIN-V-FIT

PLGA@,5Fu NPs

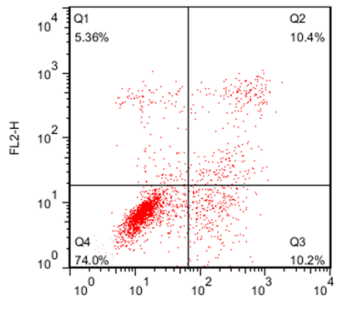

FI 1-H' ANNFXIN-V-FITC,
Blank NPs

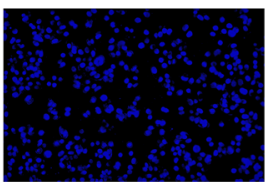

Blank NPs

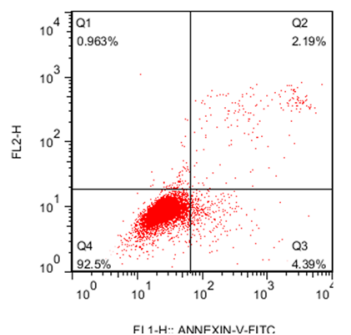

PLGA@5Fu/PFC NPs

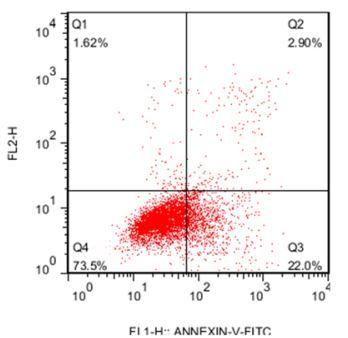

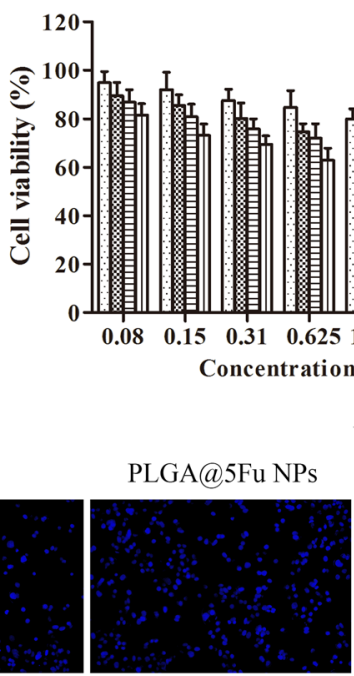

$5 \mathrm{Fu}$

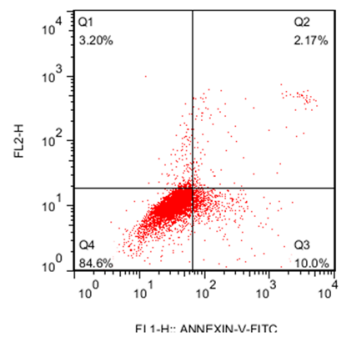

EGF-PLGA@5Fu/PFC NPs

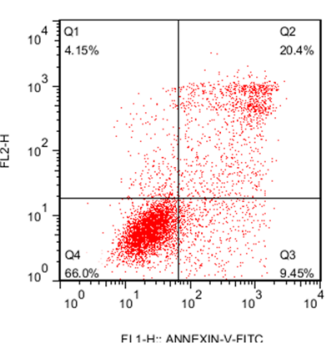

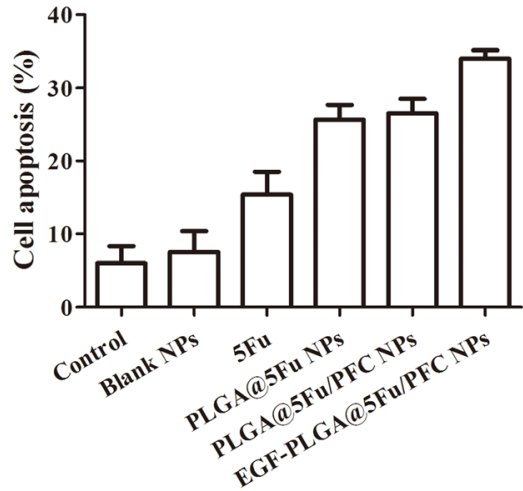

Fig. 3 Effects of EGF-PLGA@5Fu/PFC NPs on the proliferation and apoptosis in SW620 cells. a Cell viability of SW620 cells was assessed using the CCK-8 assay. $\mathbf{b}$ Apoptosis of SW620 cells was evaluated by Hoechst33342 staining (magnification, $\times 200$ ). c Apoptosis of SW620 cells was evaluated by flow cytometry 
blank NPs, 5Fu, PLGA@5Fu NPs, PLGA@5Fu/PFC NPs and EGF-PLGA@5Fu/PFC NPs. As shown in Fig. 3a, CCK-8 assay results indicated that free 5Fu, PLGA@5Fu NPs, PLGA@5Fu/PFC NPs and EGF-PLGA@5Fu/PFC NPs inhibited the proliferation of colon cancer cells in a concentration-dependent manner. In addition, treatment with EGF-PLGA@5Fu/PFC NPs resulted in more pronounced suppression of SW620 cell proliferation than that resulting from treatment with PLGA@5Fu/PFC NPs, PLGA@5Fu NPs or free 5Fu. In contrast, EGFPLGA did not exhibit cytotoxicity toward SWS620 cells.

Cancer cells typically undergo apoptosis in response to exposure to antitumor agents. To evaluate apoptosis induced by $5 \mathrm{Fu}$-loaded NPs, SW620 cells were stained with Hoechst33342 to observe apoptotic morphology. As shown in Fig. 3b, cells treated with free 5Fu, PLGA@5Fu NPs, PLGA@5Fu/PFC NPs or EGF-PLGA@5Fu/PFC NPs exhibited apoptotic features to differing degrees, as evidenced by nuclear fragmentation and chromatin condensation. Furthermore, cells treated with EGFPLGA@5Fu/PFC NPs showed more pronounced apoptotic features compared to those observed following treatment with the other compounds and formulations. In contrast, blank NPs did not significantly impact cell morphology.

Antitumor effects were further evaluated using flow cytometry. Treatment with EGF-PLGA@5Fu/PFC NPs (34\%) induced a higher rate of apoptosis than that observed in response to free 5Fu (15.4\%), PLGA@5Fu NPs (26\%) or PLGA@5Fu/PFC NPs (26.5\%) (Fig. 3c). These results indicated that inclusion of EGF in EGFPLGA@5Fu/PFC NPs enhanced suppression of proliferation and induced apoptosis via anchoring of $5 \mathrm{Fu}$-loaded NPs to the surface of SW620 cells, which resulted in the accumulation of $5 \mathrm{Fu}$ in tumor cells.

\section{In vivo antitumor effects of PLGA nanoparticles}

To investigate the in vivo distribution of 5Fu-loaded NPs, tumor-bearing mice were injected with Cy5-labeled NPs via tail vein injection. Tumors and major organs were then removed and imaged ex vivo. The results indicated that mice treated with EGF-PLGA@5Fu/PFC NPs

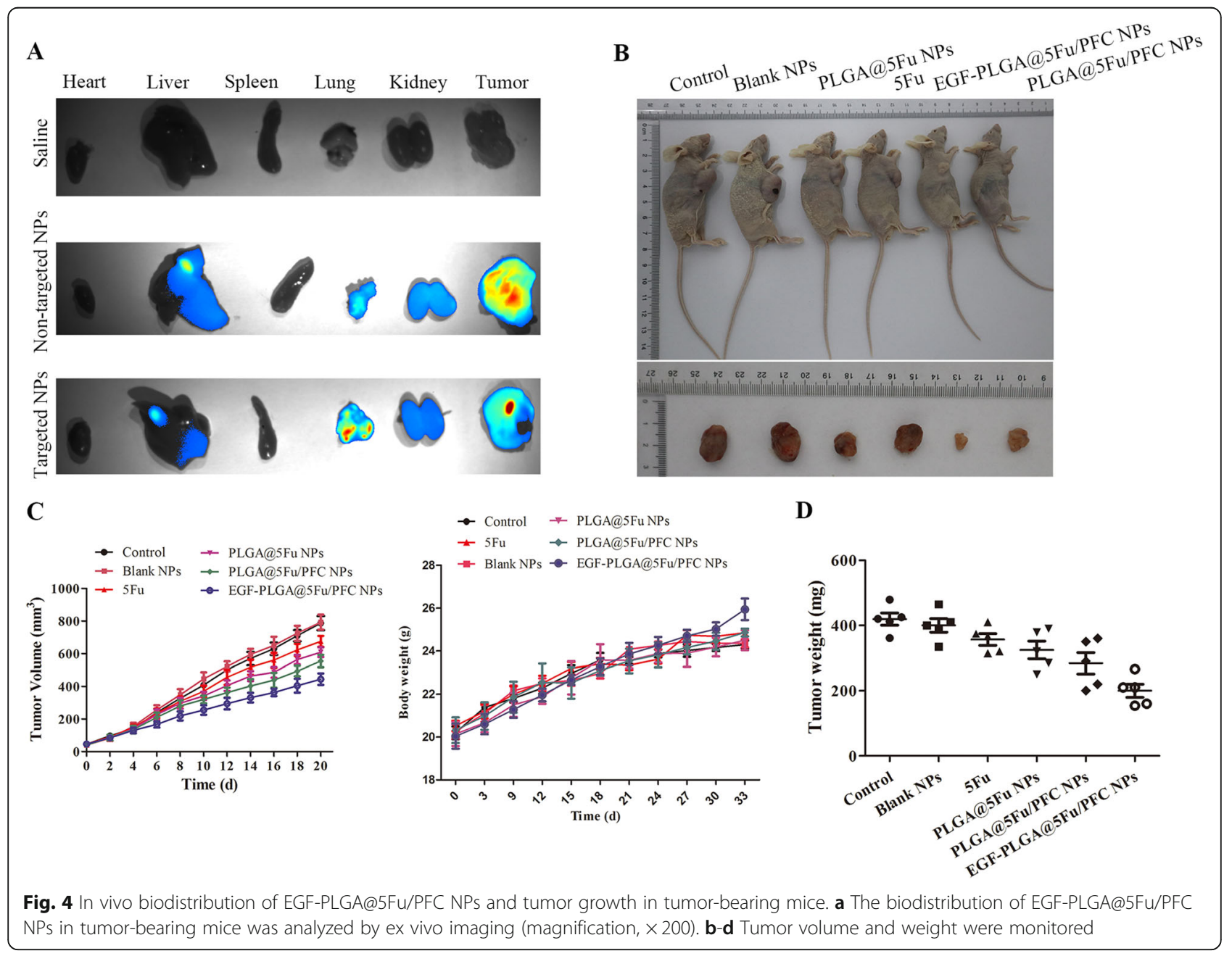


exhibited obviously stronger fluorescence signal at the tumor site than that observed in response to PLGA@5Fu/PFC NPs (Fig. 4a), which may have been due to EGF-mediated accumulation at tumor sites, and internalization of these NPs via ligand-receptor mediated endocytosis. Of note, significant fluorescence signal was also observed in the liver due to cellular uptake by endothelial cells and phagocytic cells. The findings suggested that EGF-targeting NPs promoted preferential accumulation at tumor sites.

To assess the chemotherapeutic effects of 5Fu loaded NPs in vivo, the tumor-bearing mice were administered with different nanoparticulate formulations. The tumor growth rate in mice treated with EGF-PLGA@5Fu/PFC NPs was significantly lower than that in the groups treated with free 5Fu,PLGA@5Fu NPs and PLGA@5Fu/PFC $\mathrm{NPs}$, and the different formulations that contained $5 \mathrm{Fu}$ induced a trend toward a decrease in tumor growth rate (Fig. 4b). These results revealed that EGF modified NPs played an important role in tumor targeting, which resulted in drug accumulation in the tumor site, and an enhanced therapeutic effect. Mice treated with saline and blank NPs showed the fastest tumor growth rates. Evaluation of tumor volumes and weights for 20 days after injection showed that EGF-PLGA@5Fu/PFC NPs were the most effective treatment evaluated (Fig. $4 \mathrm{c}$ and d).

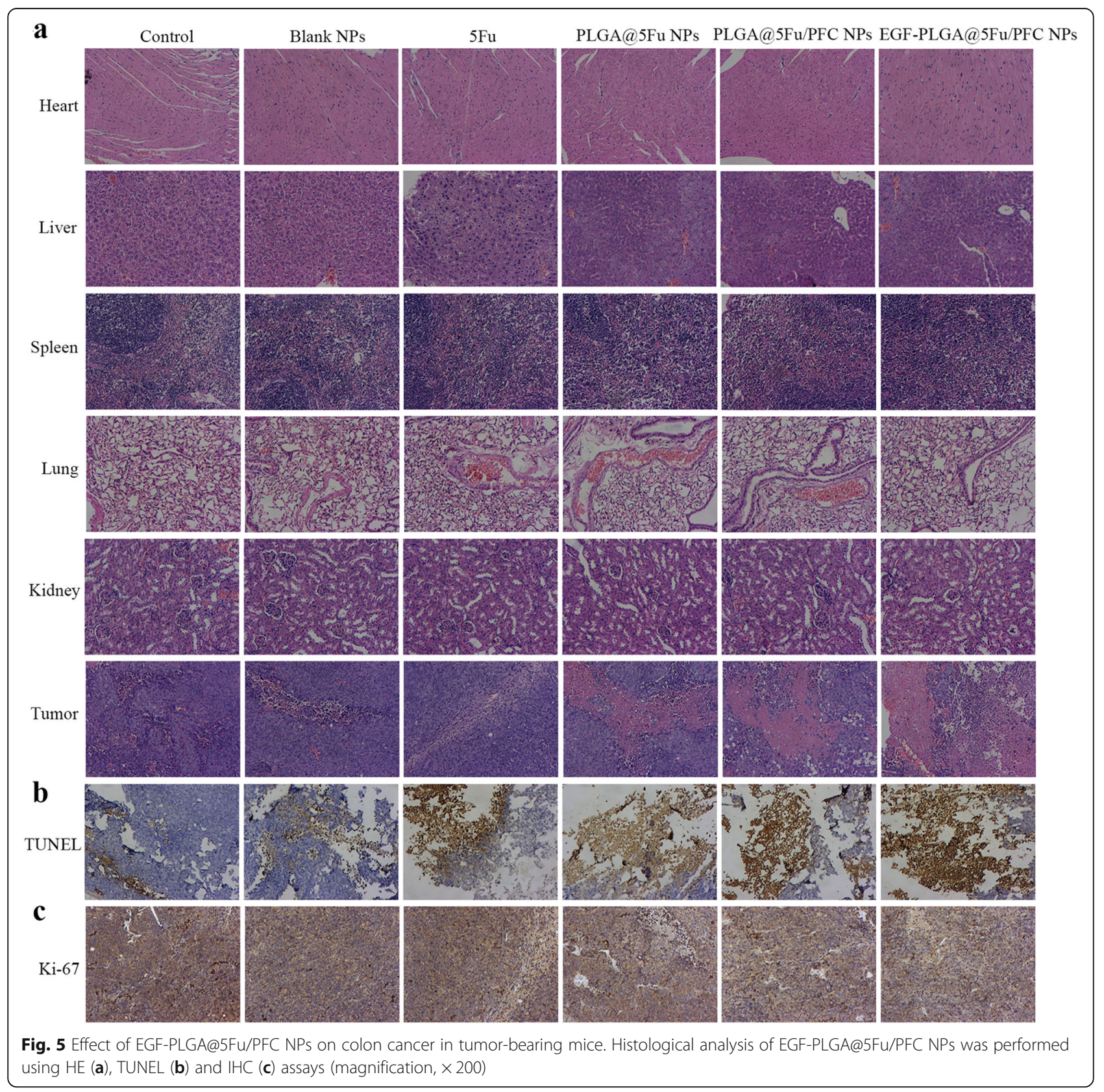




\section{Histological analysis}

The effects of 5Fu-loaded NPs on major organs and tumor tissues were evaluated using H\&E staining, TUNEL staining and IHC. As shown in Fig. 5a-c, the different drug formulations induced differing degrees of tumor necrosis. Tumor necrosis was highest in the EGF-targeted NPs group. Furthermore, the greatest hepatic toxicity was observed in the free $5 \mathrm{Fu}$ group, which was the most common first-pass effect-associated side effect of chemotherapeutic drugs. The results obtained using H\&E staining were also confirmed by TUNEL and IHC assays.

These results suggested that PLGA@5Fu/PFC NPs was more effective at inhibiting tumor growth than PLGA@5Fu NPs. We hypothesized that PFC could modulate tumor hypoxia to achieve the improved therapeutic outcomes. To test this hypothesis, we used an injectable hypoxia-specific probe to track the hypoxic status of the tumors. As shown in Fig. 6, immunofluorescence imaging showed that treatment with EGF-PLGA@5Fu/PFC NPs treatment significantly weakened pimonidazole green fluorescence compared with that in the control group, which indicated decreased tumor hypoxia. This result was consistent with the findings of a previous study that PFC could transport oxygen to tumors [20]. This finding indicated the enhanced antitumor efficacy associated with PFC-based NPs was partially attributed to improved tumor oxygenation.

\section{Discussion}

Treatment of cancer using $5 \mathrm{Fu}$ is associated with high toxicity, the need for repeated dosing and non-specific tissue accumulation. Therefore, $5 \mathrm{Fu}$ monotherapy is often insufficient for treatment of colon cancer treatment. In this study, we developed EGF-modified PLGA NPs co-loaded with 5Fu and PFC to overcome these limitations. The data indicated that EGF-PLGA@5Fu/ PFC NPs exhibited better antitumor efficacy than the other formulations evaluated in this study, as evidenced by enhanced suppression of cell proliferation, induction of cell apoptosis and attenuation of tumor growth in vitro and in vivo. Moreover, no obvious lesions were observed in major organs following treatment with NPs, which indicated that the developed NPs were safe.

Nanoparticles have potential to improve the efficacy of chemotherapeutic drugs based on improved drug targeting properties [21]. EGF is a commonly used binding agent for EGF receptor-overexpressing solid tumors including colon cancer [22]. Human SW620 colon cancer cells were chosen as model EGF receptor overexpressing tumor cells in this study to investigate the targeting ability of EGF-PLGA@5Fu/PFC NPs. The results showed increased cellular uptake of EGF-PLGA@5Fu/PFC NPs into colon cells through binding to EGF receptors on the cell surface. A previous study showed that EGF receptortargeted PLGA NPs conjugated with curcumin exhibited enhanced cellular uptake into MCF-7 cells [23]. Another study showed enhanced EGF receptor-mediated cellular

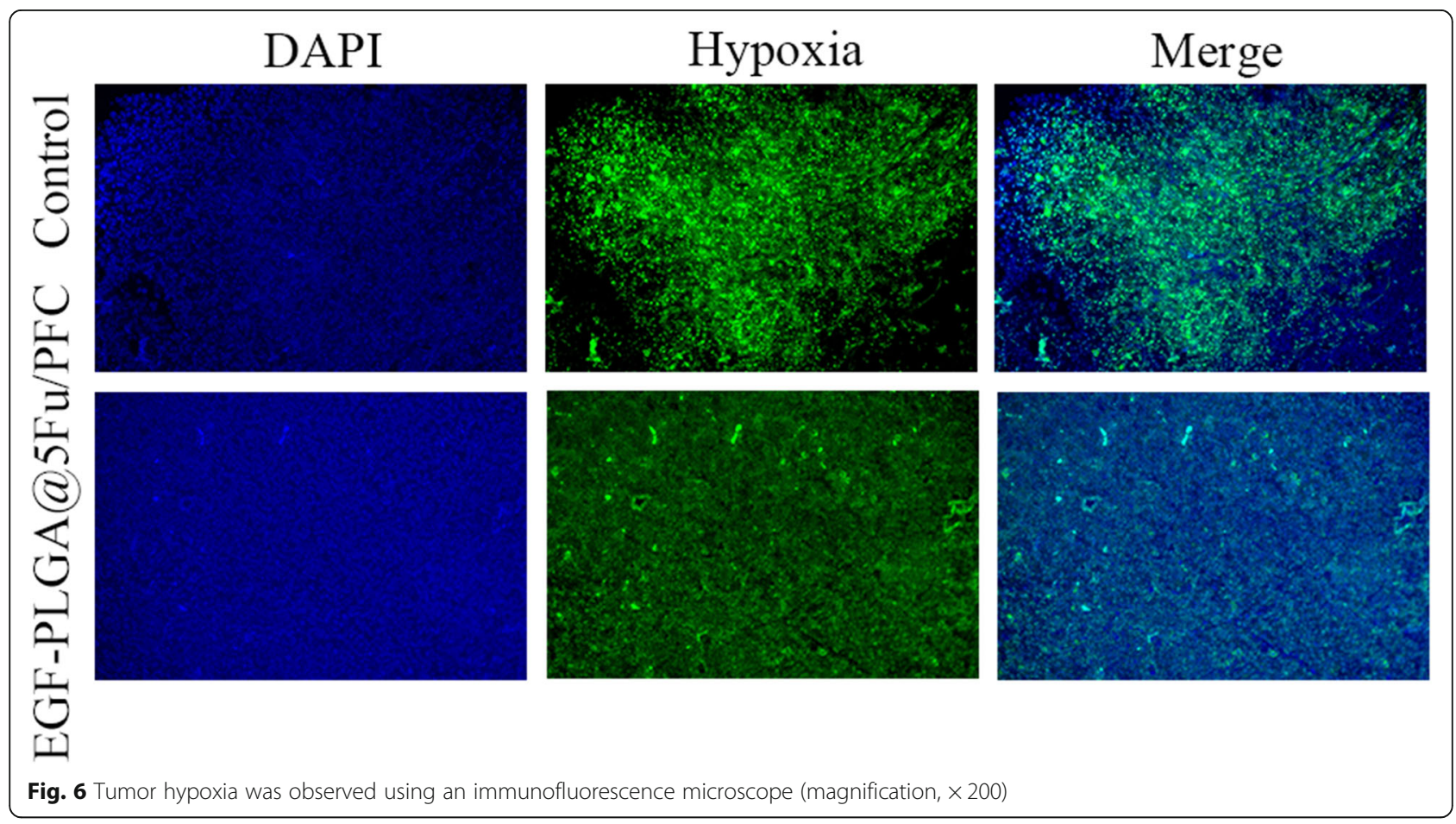


uptake of silica NPs loaded with zinc phthalocyanine into pancreatic cancer cells [24]. Thus, modification of NPs with EGF could promote the cellular uptake of NPs into tumors overexpressing EGF receptors.

Co-delivery of multiple drugs using nanocarriers provides many benefits over monotherapeutic approaches. A previous study indicated that PLGA NPs loaded with doxorubicin and curcumin induced greater antitumor effects against breast cancer as a result of curcuminmediated inhibition of P-glycoprotein (P-gp)-associated drug exclusion [25]. A self-assembled nanosystem coloaded with trichosanthin (TCS) protein and albendazole (ABZ) exhibited excellent antitumor effects through reduction of multidrug resistance [26]. Previous studies have shown that tumor hypoxia can induce chemotherapy resistance [27]. PFC, commonly used as oxygen carriers in clinical use, has been reported to promote oxygen delivery to tumor microenvironments [28]. In our study, PLGA NPs co-loaded with 5Fu and PFC showed additive antitumor effects against colon cancer, which was likely due in part to PFC-mediated diffusion of oxygen into the tumor tissue. These findings agreed with previous studies that PFC could inhibit intratumoral hypoxia $[29,30]$.

\section{Conclusions}

In conclusion, we successfully constructed a biocompatible nanodrug delivery system that could selectively accumulate in tumor via ligand-targeting interactions and overcome hypoxia-induced chemotherapy resistance via increasing local oxygen level, thereby resulting in the improved therapeutic effects.

\begin{abstract}
Abbreviations
PLGA: Poly (lactic-co-glycolic acid); FDA: Food and Drug Administration; I/ R: Ischemia/reperfusion; 5Fu: 5-fluorouracil; EGF: Epidermal growth factor; PFC: Perfluorocarbon; EDC: N'-ethylcarbodiimide hydrochloride; TEM: Transmission electron microscopy; DLS: Dynamic light scattering; DMEM: Dulbecco's Modified Eagle Medium; FBS: Fetal bovine serum; CLSM: Confocal laser scanning microscope; H\&E: Hematoxylin and eosin; IHC: Immunohistochemical staining; TUNEL: TdT-mediated dUTP nick end labeling; NPs: Nanoparticles; TCS: Trichosanthin; ABZ: Albendazole; P-gp: Pglycoprotein
\end{abstract}

\section{Acknowledgements}

Not applicable.

\section{Authors' contributions}

PW, QA, YZ and HZ performed the experiment and/or performed data analysis. PW, QA prepared the manuscript. JB contributed to the study design. All authors read and approved the final manuscript.

\section{Funding}

This project was supported by the National Natural Science Youth Foundation of China (No. 81601604), the Natural Science Youth Foundation of Jiangsu (No. BK20161070), the Fifteenth Batch High-level Talents Project of "Six Talent Peaks" in Jiangsu Province (No.WSW-049) and the talents program of Jiangsu Cancer Hospital (No. YC201809). The funding bodies played no role in the design of the study and collection, analysis, and interpretation of data and in writing the manuscript.

\section{Availability of data and materials}

The datasets used and/or analyzed during the current study available from the corresponding author on reasonable request.

\section{Ethics approval and consent to participate}

All the methodologies in animal experiment were conducted in accordance with the Guidelines for Care and Use of Laboratory Animals of the University of Science and Technology of China. This work was approved by the Animal Ethics Committee of Nanjing Medical University.

\section{Consent for publication}

Not applicable.

\section{Competing interests}

The authors declare that they have no competing interests.

Received: 30 October 2019 Accepted: 29 March 2020

Published online: 28 April 2020

\section{References}

1. Torre LA, Bray F, Siegel RL, Ferlay J, Lortet-Tieulent J, Jemal A. Global cancer statistics, 2012. CA Cancer J Clin. 2015;65(2):87-108.

2. Yaffee P, Osipov A, Tan C, Tuli R, Hendifar A. Review of systemic therapies for locally advanced and metastatic rectal cancer. J Gastrointest Oncol. 2015;6(2):185-200.

3. Din FU, Aman W, Ullah I, Qureshi OS, Mustapha O, Shafique S, et al. Effective use of nanocarriers as drug delivery systems for the treatment of selected tumors. Int J Nanomedicine. 2017;12:7291-309.

4. Yang S, Gao H. Nanoparticles for modulating tumor microenvironment to improve drug delivery and tumor therapy. Pharmacol Res. 2017;126:97-108.

5. Jeetah R, Bhaw-Luximon A, Jhurry D. Nanopharmaceutics: phytochemicalbased controlled or sustained drug-delivery systems for cancer treatment. J Biomed Nanotechnol. 2014;10(9):1810-40.

6. Santos CIAV, Ribeiro ACF, Esteso MA. Drug delivery systems: study of inclusion complex formation between Methylxanthines and Cyclodextrins and their Thermodynamic and Transport properties. Biomolecules. 2019;9(5): 54.

7. Palmerston Mendes L, Pan J, Torchilin VP. Dendrimers as Nanocarriers for Nucleic Acid and Drug Delivery in Cancer Therapy. Molecules. 2017;22(9): 1401.

8. Grigoras AG. Polymer-lipid hybrid systems used as carriers for insulin delivery. Nanomedicine. 2017;13(8):2425-37.

9. Rezvantalab S, Drude NI, Moraveji MK, Güvener N, Koons EK, Shi Y, et al. PLGA-based nanoparticles in Cancer treatment. Front Pharmacol. 2018;9: 1260

10. Lee PC, Zan BS, Chen LT, Chung TW. Multifunctional PLGA-based nanoparticles as a controlled release drug delivery system for antioxidant and anticoagulant therapy. Int J Nanomedicine. 2019;14:1533-49.

11. Cai J, Qian K, Zuo X, Yue W, Bian Y, Yang J, et al. PLGA nanoparticle-based docetaxel/LY294002 drug delivery system enhances antitumor activities against gastric cancer. J Biomater Appl. 2019;33(10):1394-406.

12. Xie X, Tao Q, Zou Y, Zhang F, Guo M, Wang Y, et al. PLGA nanoparticles improve the oral bioavailability of curcumin in rats: characterizations and mechanisms. J Agric Food Chem. 2011;59(17):9280-9.

13. Ni W, Li Z, Liu Z, Ji Y, Wu L, Sun S, et al. Dual-targeting nanoparticles: Codelivery of curcumin and 5-fluorouracil for synergistic treatment of Hepatocarcinoma. J Pharm Sci. 2019;108(3):1284-95.

14. Sharma A, Kaur A, Jain UK, Chandra R, Madan J. Stealth recombinant human serum albumin nanoparticles conjugating 5-fluorouracil augmented drug delivery and cytotoxicity in human colon cancer, HT-29 cells. Colloids Surf B Biointerfaces. 2017;155:200-8

15. Astolfi P, Giorgini E, Gambini V, Rossi B, Vaccari L, Vita F, et al. Lyotropic liquid-crystalline Nanosystems as drug delivery agents for 5-fluorouracil: structure and cytotoxicity. Langmuir. 2017;33(43):12369-78.

16. Hiremath CG, Kariduraganavar MY, Hiremath MB. Synergistic delivery of 5fluorouracil and curcumin using human serum albumin-coated iron oxide nanoparticles by folic acid targeting. Prog Biomater. 2018;7(4):297-306.

17. Handali S, Moghimipour E, Rezaei M, Ramezani Z, Kouchak M, Amini M, et al. A novel 5-fluorouracil targeted delivery to colon cancer using folic acid conjugated liposomes. Biomed Pharmacother. 2018;108:1259-73. 
18. Haggag YA, Matchett KB, Dakir EH, Buchanan P, Osman MA, Elgizawy SA, et al. Nano-encapsulation of a novel anti-ran-GTPase peptide for blockade of regulator of chromosome condensation 1 (RCC1) function in MDA-MB231 breast cancer cells. Int J Pharm. 2017;521(1-2):40-53.

19. Li K, Liu Y, Zhang S, Xu Y, Jiang J, Yin F, et al. Folate receptor-targeted ultrasonic PFOB nanoparticles: synthesis, characterization and application in tumor-targeted imaging. Int J Mol Med. 2017;39(6):1505-15.

20. Lowe KC. Synthetic oxygen transport fluids based on perfluorochemicals: applications in medicine and biology. Vox Sang. 1991;60(3):129-40.

21. Hu CM, Aryal S, Zhang L. Nanoparticle-assisted combination therapies for effective cancer treatment. Ther Deliv. 2010;1 (2):323-34.

22. Yun S, Kwak Y, Nam SK, Seo AN, Oh HK, Kim DW, et al. Ligand-independent epidermal growth factor receptor overexpression correlates with poor prognosis in colorectal Cancer. Cancer Res Treat. 2018;50(4):1351-61.

23. Jin $\mathrm{H}$, Pi J, Zhao Y, Jiang J, Li T, Zeng $X$, et al. EGFR-targeting PLGA-PEG nanoparticles as a curcumin delivery system for breast cancer therapy. Nanoscale. 2017;9(42):16365-74

24. Er Ö, Colak SG, Ocakoglu K, Ince M, Bresoli-Obach R, Mora M, et al. Selective Photokilling of Human Pancreatic Cancer Cells Using Cetuximab-Targeted Mesoporous Silica Nanoparticles for Delivery of Zinc Phthalocyanine. Molecules. 2018;23(11):2749.

25. Lv L, Qiu K, Yu X, Chen C, Qin F, Shi Y, et al. Amphiphilic Copolymeric micelles for doxorubicin and curcumin co-delivery to reverse multidrug resistance in breast Cancer. J Biomed Nanotechnol. 2016;12(5):973-85.

26. Tang Y, Liang J, Wu A, Chen Y, Zhao P, Lin T, et al. Co-delivery of Trichosanthin and Albendazole by Nano-self-assembly for overcoming tumor multidrug-resistance and metastasis. ACS Appl Mater Interfaces. 2017; 9(32):26648-64.

27. Minassian LM, Cotechini T, Huitema E, Graham CH. Hypoxia-induced resistance to chemotherapy in Cancer. Adv Exp Med Biol. 2019;1136:123-39.

28. Ahrens ET, Helfer BM, O'Hanlon CF, Schirda C. Clinical cell therapy imaging using a perfluorocarbon tracer and fluorine-19 MRI. Magn Reson Med. 2014; 72(6):1696-701.

29. Wang W, Cheng Y, Yu P, Wang H, Zhang Y, Xu H, et al. Perfluorocarbon regulates the intratumoural environment to enhance hypoxia-based agent efficacy. Nat Commun. 2019;10(1):1580.

30. Xiang Y, Bernards N, Hoang B, Zheng J, Matsuura N. Perfluorocarbon nanodroplets can reoxygenate hypoxic tumors in vivo without carbogen breathing. Nanotheranostics. 2019;3(2):135-44.

\section{Publisher's Note}

Springer Nature remains neutral with regard to jurisdictional claims in published maps and institutional affiliations.

Ready to submit your research? Choose BMC and benefit from:

- fast, convenient online submission

- thorough peer review by experienced researchers in your field

- rapid publication on acceptance

- support for research data, including large and complex data types

- gold Open Access which fosters wider collaboration and increased citations

- maximum visibility for your research: over $100 \mathrm{M}$ website views per year

At BMC, research is always in progress.

Learn more biomedcentral.com/submissions 